\title{
Influences of Hippocampal Place Cell Firing in the Awake State on the Activity of These Cells During Subsequent Sleep Episodes
}

\author{
Constantine Pavlides and Jonathan Winson \\ The Rockefeller University, New York, New York 10021
}

\begin{abstract}
Rat hippocampal (CA1) complex spike "place cells" of freely behaving rats were recorded in pairs continuously during a series of waking (exploration and still-alert), drowsy (quietawake), and sleeping (slow-wave, pre-rapid-eye-movement and rapid-eye-movement sleep) behaviors. Pairs of units were selected that had nonoverlapping place fields. The rats were restricted from entering the place field of either cell overnight, and on the day of recording cells were exposed to their individual place fields independently and in a counterbalanced manner. Following exposure, recordings were made in the subsequent sleep episodes and the firing characteristics of both cells were analyzed.

Following exposure, significant increases in the spiking activity of the exposed cell were observed in the subsequent sleeping states that were not evident in the unexposed cell. The increased activity was observed in the rate of firing (spikes/sec), the rate of occurrence of bursts with multiple spikes, as well as the number of bursts displaying short (2$4 \mathrm{msec}$ ) interspike intervals.

The findings suggest that neuronal activity of hippocampal place cells in the awake states may influence the firing characteristics of these cells in subsequent sleep episodes. The increased tiring rates along with the greater number of multiple spike bursts and the shorter interspike intervals within the burst, following exposure to a cell's place field, may represent possible information processing during sleep.
\end{abstract}

It is currently widely accepted that the hippocampal formation and related structures play an essential role in learning and memory. Lesion studies in humans indicate that destruction of the medial temporal lobe produces severe memory deficits (for review, see Squire, 1986). Furthermore, rccent cvidencc suggests that lesions confined to the CAl field of the hippocampus can produce comparable memory loss (Zola-Morgan et al., 1986). Memory deficits have also been reported in animals following destruction of the hippocampal formation and related structures (Olton, 1983; Squire and Zola-Morgan, 1983; Mishkin et al.,

\footnotetext{
Received Oct. 14, 1988; revised Jan. 19, 1989; accepted Feb. 16, 1989.

This work was supported by NIMH Research Scientist Development Award 5-KO2-MH 00232, NSF grants BNS 8209875 and 8706053 and a grant from the Harry F. Guggenheim Foundation to J.W. We wish to thank Paul Roosin for his help in the computer programing, Dr. Yoram Greenstein and Mark Grudman for their help with the data analysis, Drs. Steve Fox and John Kubie for providing the design of the unit discriminator and instructions in the construction of the electrode assembly, Dr. Jim Ranck for his helpful comments on a preliminary version of the manuscript, Drs. Thom Frumkes and Richard Bodnar for their support and encouragement, and Dr. Hiroshi Asanuma for his continued support.

Correspondence should be addressed to Constantine Pavlides, Box 298, The Rockefeller University, 1230 York Avenue, New York, NY 10021.

Copyright (C) 1989 Society for Neuroscience $0270-6474 / 89 / 082907-12 \$ 02.00 / 0$
}

1984) or the CA1 field alone (Davis et al., 1986). A particular type of memory that is especially disrupted following hippocampal lesions in rats is memory for spatial location (Olton and Samuelson, 1976; Morris et al., 1982; Kesner et al., 1988).

One may conclude from these lesion studies that learning and memory are dependent upon or subserved by neural circuitry and activity within the hippocampal formation, and a number of studies of unit activity have addressed this issue. Experiments using either classical or operant conditioning paradigms have demonstrated increased hippocampal unit activity closely correlated with specific stimulus-response-reinforcement contingencies, providing further evidence for a direct involvement of this structure in learning and memory (Segal and Olds, 1972; Deadwyler et al., 1979; Thompson et al., 1980; Berger et al., 1983; Wible et al., 1986; Eichenbaum et al., 1987).

More directly related to the present experiment, O'Keefe and colleagues observed, in freely behaving rats, that the majority of hippocampal complex spike cells (see Fig. $1 A$ ), believed to be pyramidal cells from the $\mathrm{CA} 1$ and $\mathrm{CA} 3$ fields, display "place cell" characteristics (O'Keefe and Dostrovsky, 1971; O'Keefe, 1976, 1983; O'Keefe and Conway, 1978; O'Keefe and Speakman, 1987). This finding has also been confirmed and expanded in a number of other laboratories (Hill, 1978; Olton et al., 1978; Best and Ranck, 1982; Kubie and Ranck, 1983; Muller and Kubie, 1987; Muller et al., 1987; for review, see O'Keefe, 1979). In brief, the majority of hippocampal complex spike cells in freely behaving rats increase their firing rates dramatically when an animal is situated in a particular location in space. [It should be noted, however, that in his classic study, Ranck (1973) showed that hippocampal pyramidal cells in freely behaving animals may also fire in response to environmental contingencies other than space.] A place field once established is maintained over rather long periods of time - weeks to months (Best and Thompson, 1984; Muller et al., 1987). This is true despite the fact that the animals may be removed from the environment containing the place field and reintroduced to it at some later time.

As has been shown in Ranck's original study (Ranck, 1973), as well as in a number of other experiments (Olmstead et al., 1973; Suzuki and Smith, 1985a, b), the firing rates of hippocampal complex spike cells, when not in their place fields, are strongly modified by behavior. Thus, these cells fire at their highest rates during sleep states and at their lowest rates during waking. This enhanced firing raises the possibility of memory processing during sleep. There have been several other indications that mnemonic processes may take place during sleeping states. For example, Winson and Abzug (1978) demonstrated the phenomenon of behavioral gating in the hippocampus. It was found that information processing through the hippocampal trisynaptic circuit is dependent on the behavior of the animal. 
Thus, the transmission of a stimulus through the circuit is relatively unrestricted during slow-wave sleep (SWS) but is restricted during waking states (Winson and Abzug, 1978). Recently, we have also shown in our laboratory that long-term potentiation, widely held as a model of learning and memory, can be preferentially induced if the tetanic stimuli are given in phase with the local theta rhythm (Pavlides et al., 1988). Theta rhythm in the normal animal occurs during 2 specific behaviors, exploration and rapid-eye-movement (REM) sleep. Last, it is well known that in humans mentation and dreaming occur in SWS and REM sleep, respectively. Both of these phenomena may be indicative of ongoing information processing.

The basis of the present study was the hypothesis that neuronal firing of hippocampal cells during sleeping states may possibly represent some form of memory processing and that this processing may be determined by the activity of these cells during preceding waking states. To investigate this hypothesis, the firing characteristics of hippocampal place cells were studied in waking and sleeping states. [Place cells were chosen for the following reasons: First, as indicated above, these units appear to be involved in spatial memory (O'Keefe and Speakman, 1987). Second, the activity of these cells can be brought under experimental control, i.e., by determining when an animal is permitted to enter the place field of a particular place cell.] In a counterbalanced study in which pairs of place cells were recorded simultaneously (see Materials and Methods for description), it was indeed found that the firing characteristics of place cells during sleep were altered by their activity during their awake bchaviors. Thus, if a cell fired cxtensively during awake exploration in its place field, enhanced activity was also observed during subsequent sleep episodes. In addition, our results present the first detailed normative data on the firing and bursting characteristics of CAl cells in a series of waking and sleeping behaviors.

\section{Materials and Methods}

Subjects. Male hooded rats (300-350 gm; Charles River Labs) were used. The animals were housed in colony cages with littermates until shortly before surgery. Subsequently, each animal was housed individually in a Plexiglas cage lined with Purina bedding material. Purina rat pellets and water were available ad libitum except that food was removed the night before the day of testing and was reintroduced at the completion of the test. The animals were rewarded randomly on all parts of a box or an 8-arm maze used for testing with precision food pellets (see below).

Electrode preparation. A multimicrowire electrode assembly was used for recording (see Kubie, 1984, for details). Briefly, the assembly consisted of 10 microwires [electroloy $(60 \%$ nickel, $15 \%$ chrome, and $25 \%$ iron) $22.5 \mu \mathrm{m}$ in diameter, HiMOL insulated wire (Molecu-wire, Corp., Wall Township, NJ)] threaded through a 26-gauge syringe and attached to an Augat connector. A stage was then constructed of cement holding the electrode bundle and Augat connector, as well as 3 screws that served to make the electrodes movable in the vertical direction. After the $10-$ wire bundle was assembled the microwires were cut $(2.5 \mathrm{~mm}$ below the syringe tubing) at a $10^{\circ}$ angle. The $10^{\circ}$ angle cut separated the 10 electrode tips by a total of $100 \mu \mathrm{m}$. In its final placement, the tips of the electrode array spanned the width of the pyramidal cell layer allowing for maximal yield of units. This was particularly important for the present study, which required the simultaneous recording of 2 complex spike cells (see below). In addition to the 10 -microwire recording assembly, 2 screw electrodes were also implanted (see below)

Surgery. Animals were anesthetized with a $40 \mathrm{mg} / \mathrm{kg}$, i.p. injection of chloral hydrate-pentobarbital (Chloropent; Fort Dodge Labs, Fort Dodge, IA; with supplemental doses as required) and mounted in a stereotaxic instrument (Kopf), the skull set level on the bregma-lambda plane. Four small holes were drilled to receive anchor screws, 2 just anterior to bregma, on either side of the midsagittal suture, 2 just anterior to lambda line on either side of the midsagittal suture, and a fifth hole drilled for the implantation of the electrode assembly [coordinates: 4.1 $\mathrm{mm}$ posterior to bregma, $2.6 \mathrm{~mm}$ lateral to the midsagittal suture (left hemisphere), and $2.1 \mathrm{~mm}$ ventral to skull surface]. One of the 2 anterior screw electrodes, placed above the frontal bone, served as an indifferent for recording the animal's electroencephalogram (EEG), while the second was used to ground the animal to the equipment. With the screws mounted, the dura matter was severed and the 10 microelectrode assembly was lowered $2.1 \mathrm{~mm}$ ventral to the skull surface. This initial electrode placement located the electrodes approximately $0.3 \mathrm{~mm}$ above the CAl pyramidal field of the hippocampus. Following surgery, the animals were given a local antibiotic (Panolog ointment) to prevent infection and were allowed to recover for approximately 1 week before testing began.

Testing apparatus. A small number of animals were tested in a rectangular box $(112 \times 65 \times 112 \mathrm{~cm})$ in which one of the sides was open and a drop door was available that could close the box. A light bulb, covered with a frosted glass, was placed on the ceiling of the box. An exhaust fan, at the side of the box, operated at all times. The fan not only provided sufficient air circulation but also produced white noise to prevent disturbance of the animal's sleeping behavior by external noises. Constant monitoring of the animal's behavior was performed via a closed-circuit TV system. Visual monitoring of the animal could also be done through a 1 -way mirror placed on the front door. The box was divided into smaller compartments with clear Plexiglas partitions. This was important for keeping the animal in or out of a particular place field. A second group of animals was tested on an 8-arm maze. The maze consisted of 8 equally spaced arms $(10 \times 60 \mathrm{~cm})$ attached to a center platform $(34 \mathrm{~cm}$ wide). The center platform was raised $85 \mathrm{~cm}$ off the floor. Easy detachment of each of the arms was possible. Testing took place with the maze located at the center of an approximately square room ( $3 \mathrm{~m}$ long by $2.75 \mathrm{~m}$ wide). The room had a window, a desk, bookcases with books, the testing equipment, and the experimenter. The animal's view of the environment was not obstructed in any way. Monitoring of the animal's behavior was achieved with a closed-circuit TV system with the camera mounted on a tripod at the side of the maze. Almost all sleep took place on the center of the maze with all of the arms detached. It should be noted that it was determined in advance that no spatial fields for either cell existed on the center of the maze. In a minority of cases in which there appeared to be a place field on the center, the animal was restricted and slept on one of the arms that did not have a place field (see below for further details). None of the animals was tested in both the box and the maze.

\section{Data acquisition and analysis}

Unit recording procedure. Unit recording was performed as follows: A male Augat, fitted with field-effect transistors (FET; source-follower configuration) in order to eliminate movement and other recording artifacts, was attached to the headstage of the animal. Three shielded, triple conductor cables (Cooner Wire Co., Clatsworth, CA) on the other side of the connector led the signal from the animal to an 8-pin commutator (Micco, 1977). The commutator was attached to one end of a counterbalanced, swinging arm that was fixed to the ceiling directly above the center of the testing box or the 8-arm maze. This allowed the animals to move freely or sleep on the 2 testing apparatuses without entangling the wires. The unit signals were then led to a Grass amplifier (model 7P511) with the filters set between $3 \mathrm{~Hz}-3 \mathrm{kHz}$. Further filtration, to detect unit activity was achieved with a high-pass active filter (cut-off at $300 \mathrm{~Hz}, 24 \mathrm{~dB} /$ octave; custom built, Rockefeller University electronics laboratory). The signals were recorded on the 2 audio channels of a video cassette recorder (Sony Beta I) for later analysis. The signals were also led simultaneously to a window discriminator for unit discrimination (to be described later), and finally to a digital oscilloscope (Tektronix, model 5223) for on-line viewing.

Testing procedure. Following postoperative recovery, the animals were placed on the testing apparatus and allowed to acclimate for 2 or $3 \mathrm{~d}$. The animals were trained to traverse the entire testing box or all the arms of the maze in search of food pcllets, randomly placed throughout both apparatuses. Following the initial acclimation and training periods, the animals were attached to the testing equipment and the search for units proceeded. In the event that no units were located on any of the 10 electrodes, the whole electrode assembly was lowered by $25 \mu \mathrm{m}$ steps by screwing the 3 screws on the top of the electrode assembly in a clockwise direction $(1 / 16$ turn $=25 \mu \mathrm{m}$ ). After approximately $2 \mathrm{hr}$ (allowed 
for the electrodes to settle in the brain), all the electrodes were tested again for the availability of place cells. $\Lambda$ ll testing for place cells and subsequent sleep recording took place in a single testing apparatus (i.e., either the box or the 8-arm maze). An exact record of the electrode movement was recorded in order to calculate the precise location of the electrodes at the completion of the experiment. This procedure was repeated until 2 well-discriminable units (signal to noise ratio of over 3:1) with different place fields were encountered. In the event that this was accomplished, actual recording began.

As previously mentioned, the objective was to be able to record from 2 units with nonoverlapping place fields simultaneously. Thus, when 2 or more units were available, the animal was enticed to traverse the entire box and all of the arms and the place fields were carefully documented. A location on the maze was labeled a place field if the unit increased its fring at least 3-fold compared with adjacent positions on the box or maze (see below for further details). If 2 units with welldifferentiated and nonoverlapping place fields were located, the animal was put in its home cage, which was placed on top of the 8-arm maze at its center. Both units were monitored in the home cage for place field firing. If none was observed, the animal was accepted for testing and remained in its home cage overnight. (In the occasional case in which there was a place field in the center of the maze, the same procedure was followed with the exception that the home cage was placed overnight on an arm that did not have a place field. Subsequent sleep episodes during testing, as described below, also occurred on that arm.)

On the following morning, the animal was hooked up to the equipment while in its home cage on the maze, and both units were checked to see whether a place field had developed in the home cage for either unit. In the event that none existed, the animal was placed on the 8arm maze and the place fields of both units were briefly checked to make sure that they were still present. With the place fields verified, the animal was placed on the center of the maze (with all arms removed) or a part of the testing box that contained no place fields for either unit and allowed to stay there for at least $2 \mathrm{hr}$. Since rats are nocturnal, after a brief exploratory period the majority of them would settle down and sleep. Unit activity, $E E G$, and behavior were recorded during this entire "baseline" period.

Following baseline recording, the arm containing the place field of one of the units was reattached to the maze, the animal was placed on this arm and was left there for approximately 10-15 min. Similarly, when animals were tested in the box, they were partitioned on the quadrant that contained the place field of one of the cells and were allowed to stay there for a similar amount of time. During this period, the unit fired at the high rates characteristic of the place field. In the majority of cases, the animal was either in an alert state or else would be engaged in exploratory behaviors while in the place field. In a minority of cases, the animal would attempt to move away from the place field, in which case it had to be actively restrained there by holding. At the end of this "exposure" period, the animal was placed back on the center of the maze or the section of the box that contained no place fields and kept there for a number of SWS-REM cycles (for at least 2 $\mathrm{hr}$ ). In the case of the maze, the arm containing the place field was removed during this time. The firing activity of the second unit that was not exposed to its place field was also recorded throughout this period. Subsequently, the second unit was similarly exposed to its respective place field and the procedure was repeated, again both cells being recorded simultaneously. At the end of all sleep recording, all the arms were replaced on the maze and each arm was checked for place fields. This was performed to ensure that the place fields were still intact for both cells. At the end of a successful experiment, the electrode assembly was advanced in $25 \mu \mathrm{m}$ increments and the search for additional units continued. When the electrode assembly passed through the pyramidal layer, the animal was killed and histologic analysis was performed to determine the location of the recording site (see below for details). In all, 13 units were recorded successfully. These consisted of 6 pairs of counterbalanced units, one "pair" consisting of 3 units. In this last case, units 2 and 3 served as control for unit 1 and unit 1 served as a control for units 2 and 3 .

Unit discrimination. Unit discrimination was achieved through the use of a custom-built, dual digital window discriminator (Rockefeller University electronics laboratory). Available on the discriminator were 3 adjustable voltage levels and an adjustable time window. The signal to be discriminated had to fulfill all of the specified window restrictions to register as a spike. The 3 voltage levels were: a voltage trigger $(\mathrm{Vt})$, a voltage high (Vh), and a voltage low (Vl) level. The time windows consisted of a time width (Tw) set at a chosen time delay (Td) (see Fig. $1 B$ ). If all the parameters were met, the discriminator produced both a $0.4 \mu \mathrm{sec}$ TTL and a $+15 \mathrm{~V}$ output. A digital display of the output was also available on the discriminator.

A number of criteria had to be met before units would be selected for further recording and analysis. These criteria were as follows: (1) the units had to display complex spikes during the initial course of testing; (2) units had to have a signal-to-noise ratio of at least 3-to-1; (3) the cells had to display clear and discrete place fields; (4) at least 2 units with the above-mentioned characteristics had to be present simultaneously and to display diverse, nonoverlapping place fields. It should be noted that the firing characteristics of all the complex spike cells reported here represent averages of unit firing in many episodes within a particular behavioral state, recorded over the entire period of observation of approximately 5-6 hr.

Identification of behavioral state. Besides recording from one or more hippocampal units simultaneously, the hippocampal EEG was also recorded differentially between one of the hippocampal electrodes and the skull screw indifferent. The signal was fed to a Grass amplifier (model 7DAF) and filtered between 3 and $20 \mathrm{~Hz}$ ( $24 \mathrm{~dB} /$ octave), for clear detection of the various behavioral states (to be discussed below). The $\mathrm{EEG}$ signal was viewed on 1 of the 3 oscilloscope channels available and was also recorded with a video camera (RCA, model TC2011, with $16 \mathrm{~mm}$ lens) from 1 of the 3 oscilloscope channels for off-line analysis. This was achieved by monitoring the oscilloscope screen which was displaying the firing of 2 units and the EEG trace.

The animal's behavior was recorded with a second video camera (RCA, model TC2011/U ultracom) equipped with a manual zoom lens $(12.5-75 \mathrm{~mm})$ for close observation of the animal's behavior. This camera rested on a tripod on the side of the testing box or the side of the 8 -arm maze. The 2 video signals were fed into a splitter-inserter (RCA TC1417A) and were then fed into the single video input of the Sony Beta system (SLO-323) and recorded on Sony Dynamicron L-500 or L-750 video cassette tapes. The input of the video display (RCA, 35 $\mathrm{cm} \mathrm{B} / \mathrm{W}$ monitor, model TC1214) was split into 2 , one of the these showing the animal's behavior, while the second was showing the signals of 2 units and the hippocampal EEG. An RCA date-time generator (TC1440B) displayed the date and time while recording was taking place and during playback.

The animal's behavior was subdivided into 7 different categories. These included a number of awake behaviors: exploration (XPL); stillalert (SAL), characterized by a low-amplitude, irregular EEG; and inplace field (IPF), which could include any awake behavioral state including exploration, still-alert, or consummatory behaviors. (Regardless of the animal's behavior, place field firing was at a very high rate.) A quiet-awake (QA) state was also discriminated: animal lying still with an increase showing in the EEG amplitude and the appearance of slowwave spikes. Based on both the animal's EEG in which sporadic slowwave spikes appeared, and its quiet behavioral state from which the animal normally drifts into SWS, this may be considered a drowsy state intermediate between waking and SWS. Three sleeping states were distinguished: SWS, large increase in EEG amplitude and the appearance of large irregular slow-wave spikes; pre-rapid-eye-movement (PREM), EEG begins to synchronize, the animal's breathing becomes heavier, whisker movements become apparent; and, following PREM, rapideye-movement REM, evidenced by theta rhythm (4-8 Hz synchronized EEG), eye and whisker movements, heavy, irregular breathing, and head collapsing to the floor of the maze or box. Each particular sleep state was determined by observing an animal's behavior in the video display monitor and also observing the animal's EEG.

Analysis of data. Data analysis was performed as follows: the video tapes were played back and the unit signals were fed again to the unit discriminator with its windows set to discriminate a single unit. The animal's behavior along with the EEG were displayed on the video monitor. These 2 criteria were used to subdivide the animal's behavior into the 7 different categories (described above). Almost all data were analyzed by the primary investigator. In a number of cases, a second person, blind to the experimental design, performed the data reduction. This was done to eliminate any experimenter effects.

The TTL output of the discriminator was fed into the custom-built input/output (I/O) card (Dejong, 1982) that was installed into an Apple IIe computer. The I/O card consisted of dual precision timers $(6522$ microprocessor), which in combination with custom written software performed the task of analyzing the bursting characteristics of the units for this study. Briefly, a data-acquisition program (written in machine 


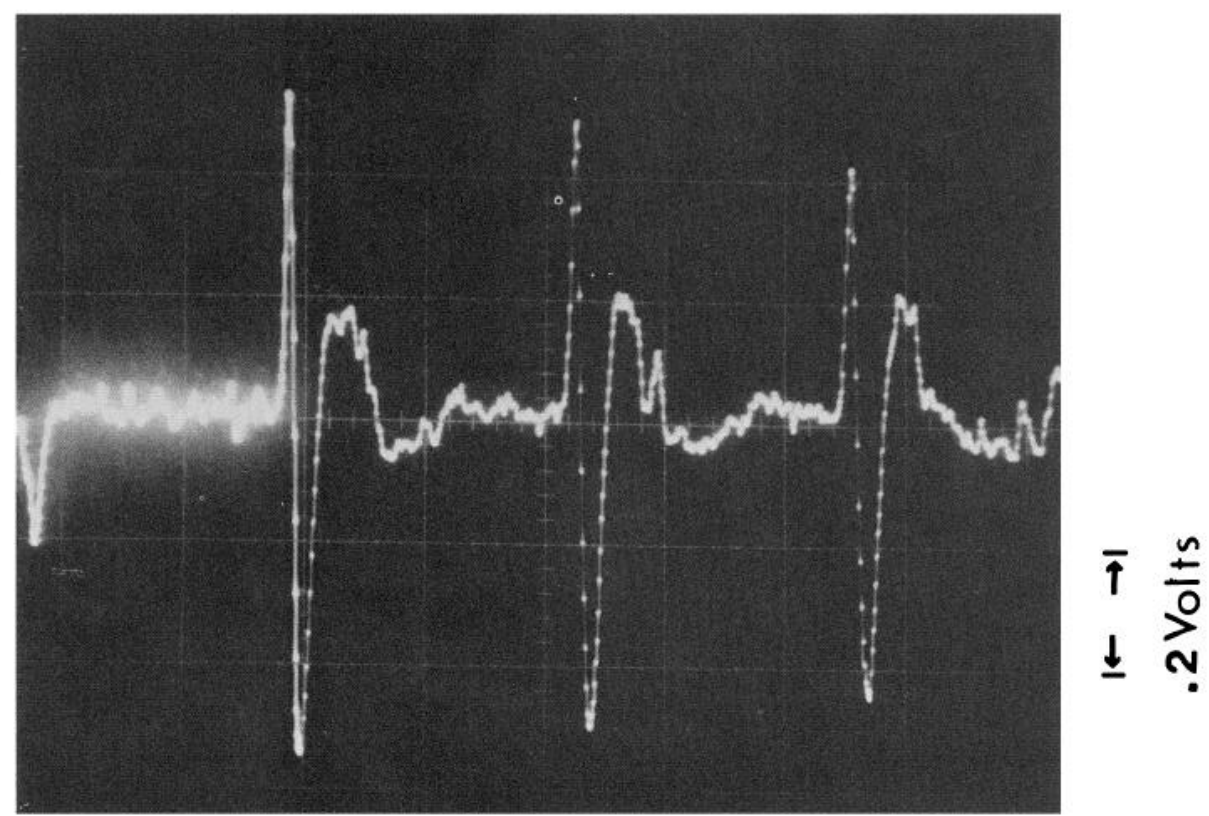

$1 \leftarrow \rightarrow 1$

\section{$2 \mathrm{Msec}$}

Figure 1. A, Oscilloscope trace of an extracellularly recorded complex spike burst. Note the decreasing amplitude of successive action potentials. Calibrations: $0.2 \mathrm{mV}, 2 \mathrm{msec}$; negativity upward. See text for filter settings. $B$, Oscilloscope trace of extracellularly recorded action potential along with markers showing adjustable discriminator settings. Marked on the photograph are the following voltage levels: voltage trigger $(V t)$ through which the signal has to pass, the voltage high $(V h)$ that must not be exceeded, and the voltage low $(V I)$ through which the signal must pass. The voltage zero $(\mathrm{VO})$, or baseline, is also marked. Further shown is an adjustable time window (horizontal dots, identified by $T w$ ), during which time the action potential must pass through the V1. The start of the time window is determined by the setting $T d$. In order for a signal to register, it had to satisfy all of the set parameters. Negativity is upward.

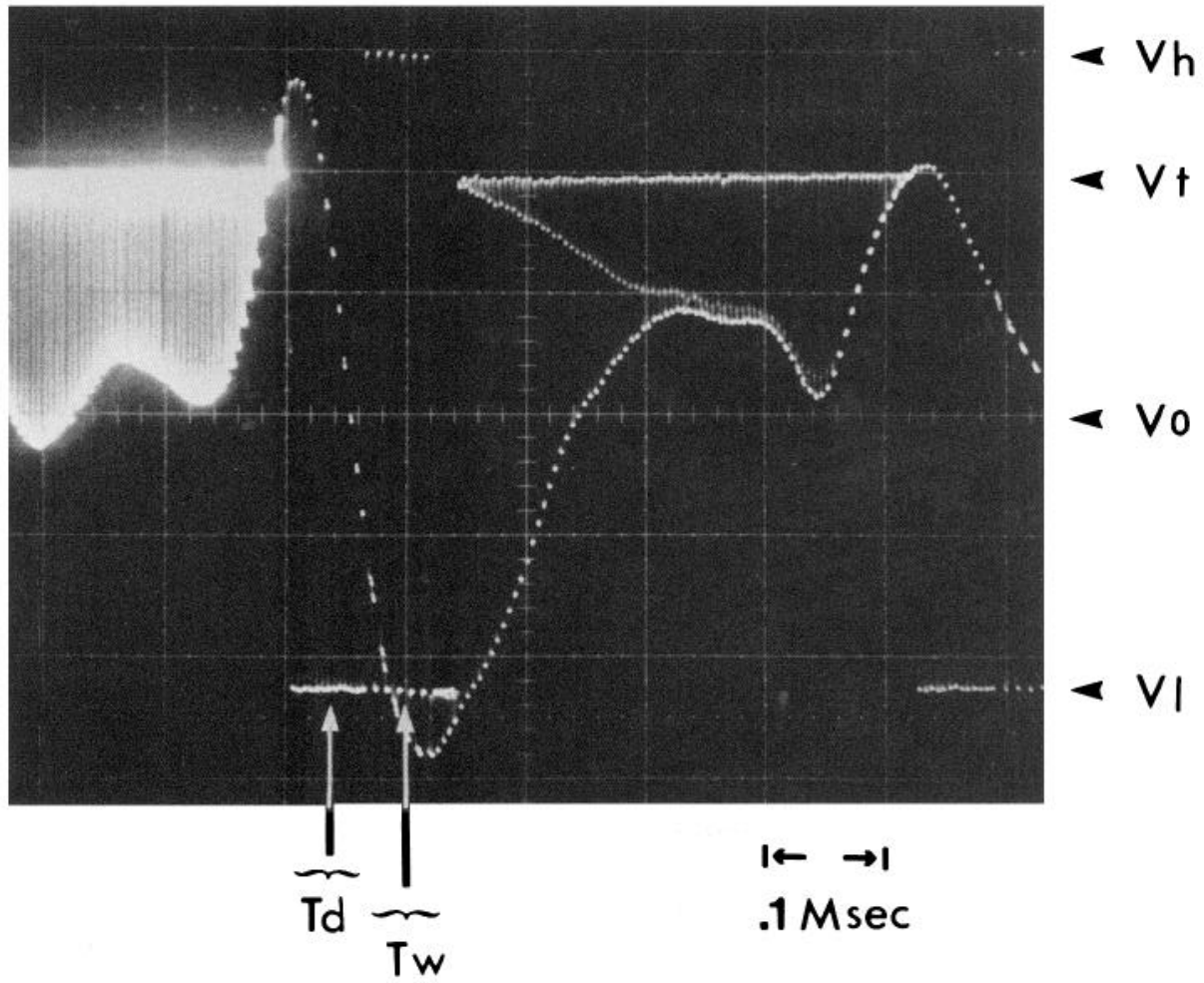


language to permit various calculations that had to be performed in microseconds) with adjustable parameters was started simultaneously with the Sony tape recorder. Once an input was detected by the I/O card, the timer was activated. If another spike appeared within a certain period of time $(10$ or $15 \mathrm{msec}$; preset at the beginning of the data analysis), then that spike was counted as part of the same burst. This was continued until the spike following the previous onc excecded the 10 or $15 \mathrm{msec}$ interval. In this case, a number of calculations pertaining to the burst were performed [i.e., interspike interval (ISI), interburst interval (IBI), number of spikes within the burst, etc.], the averages of these calculations were kept in random-access memory, and the timer was cleared and reactivated to detect the next spike or burst. This analysis continued either until the animal changed its behavioral state (as could be determined by the video tape and in sleep behaviors also aided by the animal's hippocampal EEG), or if a particular behavior was maintained for more than $5 \mathrm{~min}$, it was subdivided into $5 \mathrm{~min}$ intervals that were then averaged. In either case, the data analysis was terminated, the data were stored on floppy disks and the analysis continued for the next behavior.

Histology. At the completion of all recording in an animal, the most ventral location of the recording elcctrodes in the hippocampus was localized histologically. The exact location of a particular microelectrode was determined by the Prussian blue method. The animals were deeply anesthetized with an i.p. injection of either Chloropent $(60 \mathrm{mg} / \mathrm{kg})$ or a $2 \mathrm{ml}$ injection of sodium pentobarbital (Nembutal, Abbott Laboratories) and a $10 \mu \mathrm{A}$ current for $10 \mathrm{sec}$ was passed between one of the recording electrodes (positive) and the skull indifferent (negative). The animals were then perfused transcardially with a $9 \%$ saline solution mixed with $10 \%$ formalin, $4 \%$ potassium ferrocyanide, and $4 \%$ acetic acid. The brains were removed and stored in a $10 \%$ formalin, $40 \%$ sucrose solution for $2 \mathrm{~d}$. They were then cut by the freezing method, at $40 \mu \mathrm{m}$ section thickness, mounted on slides, and stained using the Kluver-Barrera method.

\section{Results}

\section{Histology}

Histological analysis of the rats' brains revealed that all of the 13 units included in this study were located in the dorsal part of the hippocampus. Of these, 3 were located in the CAla subfield, while the remaining 10 cells were located in the CAlc hippocampal subfield.

\section{Unit firing}

The units fired in their place field at a rate at least 3 times greater than at adjacent positions in the maze or the testing box. A place field was determined by monitoring the firing rate of a cell as the rat traversed each arm of the maze or region of the testing box. Typically, units increased their firing by a factor of 3-10 or more as the rat moved over several inches of terrain into the place field. The objective of the spatial survey was to determine locations in which the cell would fire vigorously. As seen below,

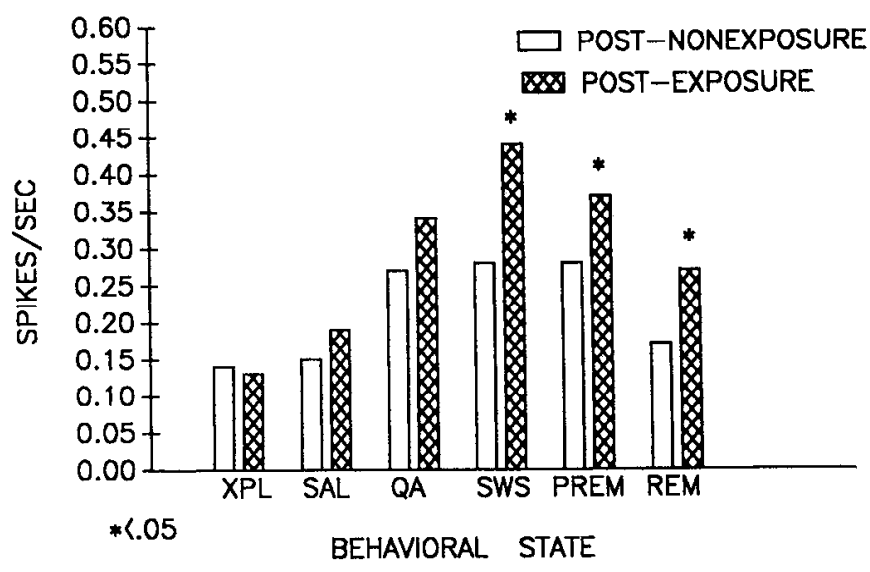

Figure 2. Average firing rate (all single spikes and spikes within a burst) post-nonexposure and postexposure to place field. There were significant increases in the firing rate during all sleep states following exposure (see text for details). (Significant increases are indicated by asterisks in this and following figures.)

firing rates within place fields on the order of 10 times the outof-place field rates were achieved. There was no attempt to define the boundaries of the place field precisely. All pairs of place cells chosen for analysis displayed distinct place fields in different places on the 8 -arm maze or box. At least half of the cells tested had multiple place fields, and the area of increased firing differed from a very small area (several inches along the arm of the maze or box) to a much wider area (half an arm of the maze or a third of the box). In all of these cases, however, incrcascd firing within one of the place fields was much greater than the other place fields. This observation was made at the time of recording, and it was utilized to determine to which of the place fields the cells were going to be exposed.

The average firing rates (in spikes/sec; each spike within a complex spike burst being counted separately) of the 13 cells, in all of the behavioral states tested, are presented in Table 1. Combining post-nonexposure to place field and postexposure to place field rates, the highest activity was observed in the IPF state $(X=2.17)$ followed by SWS $(X=0.36), \operatorname{PREM}(X=0.32)$, QA $(X=0.31), \operatorname{REM}(X=0.22), \operatorname{SAL}(X=0.17)$, and XPL $(X$ $=0.14$ ). (Note that the firing rates for post-nonexposure and postexposure were collapsed into a single mean; Table 1, line 3.)

Postexposure versus post-nonexposure to place field com-

Table 1. Rate of firing of the $\mathbf{1 3}$ complex spike (place) cells studied

\begin{tabular}{|c|c|c|c|c|c|c|c|c|c|c|c|c|c|}
\hline & \multicolumn{13}{|c|}{ Rate $^{a}$ (spikes/sec) } \\
\hline & \multicolumn{2}{|l|}{$\mathrm{XPL}$} & \multicolumn{2}{|l|}{$\mathrm{SAL}$} & \multirow[b]{2}{*}{ IPF } & \multicolumn{2}{|l|}{ QA } & \multicolumn{2}{|l|}{ SWS } & \multicolumn{2}{|c|}{ PREM } & \multicolumn{2}{|l|}{ REM } \\
\hline & nexp & $\exp$ & nexp & $\exp$ & & nexp & $\exp$ & nexp & $\exp$ & nexp & $\exp$ & nexp & $\exp$ \\
\hline Mean & 0.14 & 0.13 & 0.15 & 0.19 & 2.17 & 0.27 & 0.34 & 0.28 & 0.44 & 0.27 & 0.37 & 0.17 & 0.27 \\
\hline SD & 0.30 & 0.21 & 0.18 & 0.18 & 1.62 & 0.15 & 0.23 & 0.16 & 0.28 & 0.17 & 0.28 & 0.17 & 0.22 \\
\hline Combined & \multicolumn{2}{|c|}{0.14} & \multicolumn{2}{|c|}{0.17} & 2.17 & \multicolumn{2}{|c|}{0.31} & \multicolumn{2}{|c|}{0.36} & \multicolumn{2}{|c|}{0.32} & \multicolumn{2}{|c|}{0.22} \\
\hline
\end{tabular}

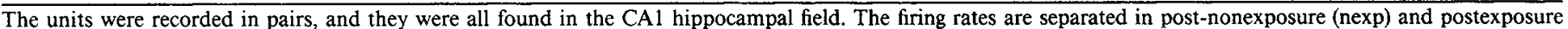

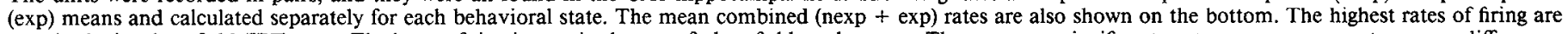

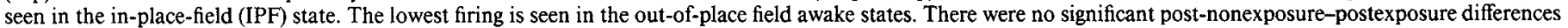

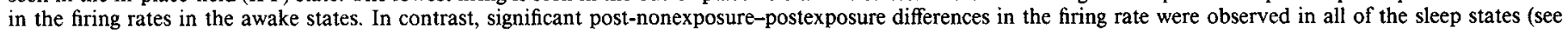
text). The large SDs reflect the wide range of firing rates among the individual units.

a All spikes within a burst measured separately. 
Figure 3. Average rate of firing during sleep and QA, post-nonexposure and postexposure to place field, for each of the 13 units included in the study. A large number of the units increased their firing rates following exposure to the place field. (This increased firing occurred in 10 of 13 cells in SWS, 9 of 13 cells in PREM, 11 of 13 cells in REM and 8 of 13 cells in QA.)
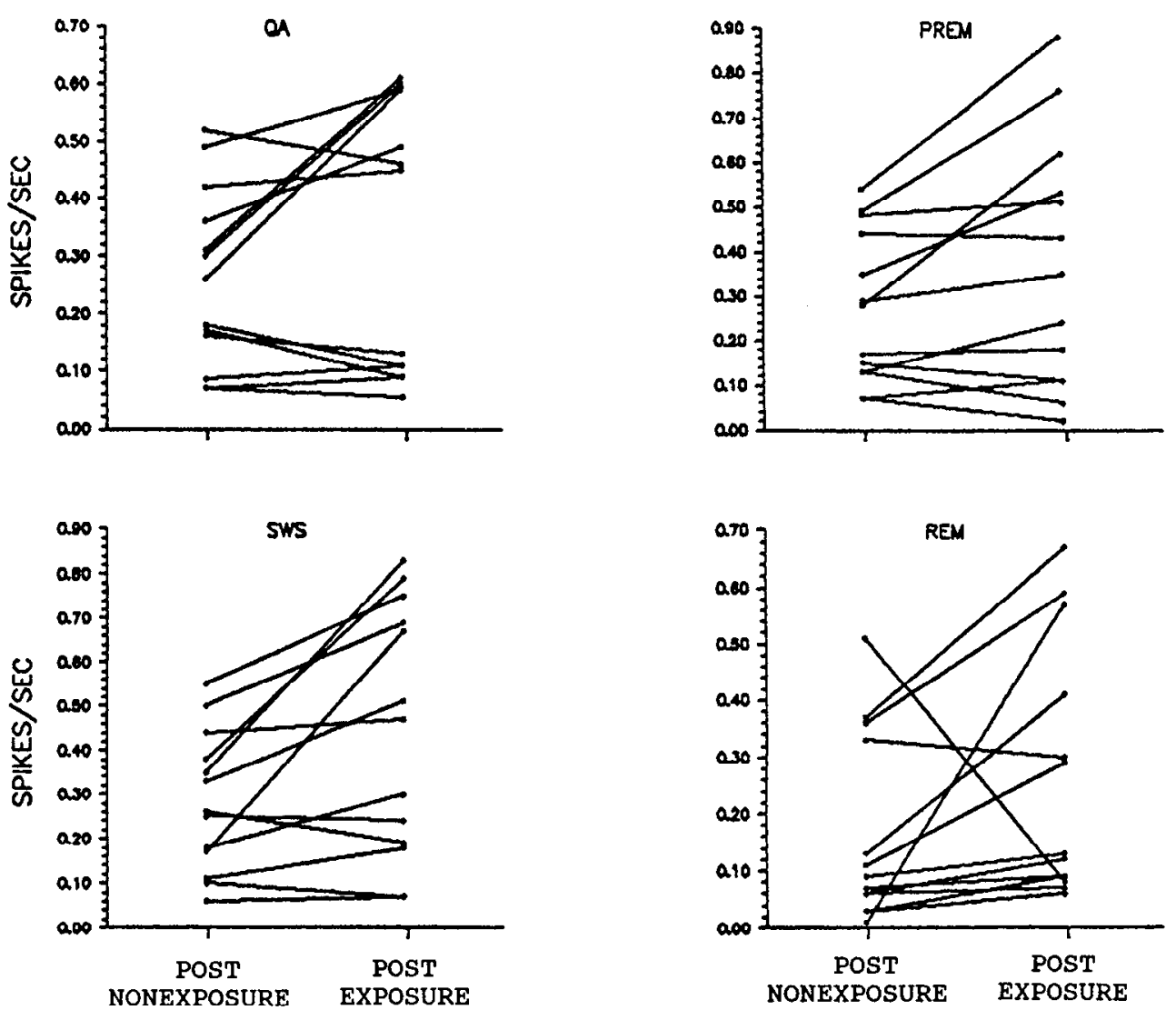

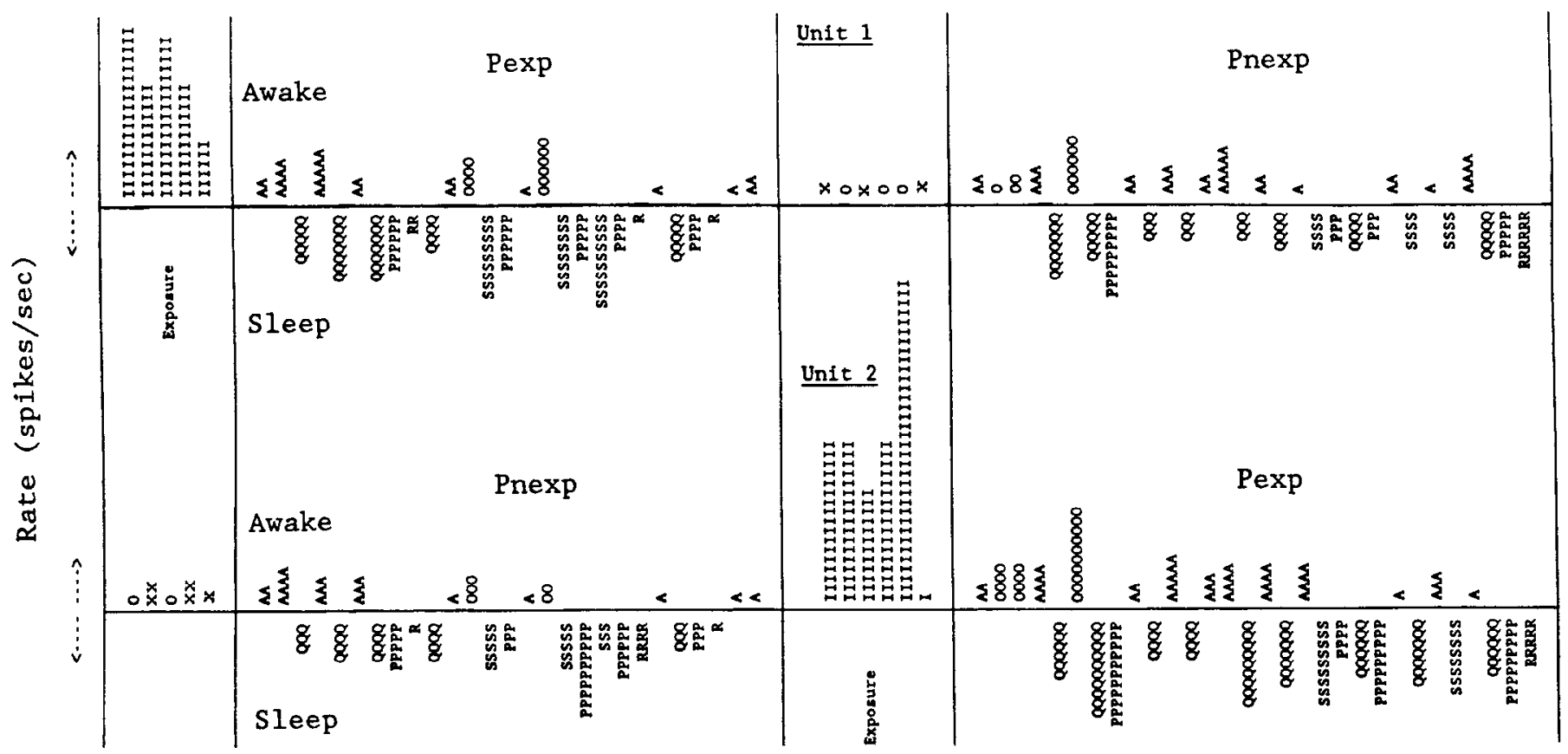

Figure 4. Histogram of firing rates for a representative pair of place cells recorded simultaneously (see text for testing procedure). Awake behaviors are shown above the horizontal line, while sleeping and drowsy (QA) hehaviors are shown below. $X, \mathrm{XPL} ; A, \mathrm{SAL} ; I$, IPF; $Q$. QA; $S$, SWS; $P$, PREM; $R$, REM; $O$, other (any behavior that did not conform to any of the above categories, i.e., feeding, chewing, grooming, etc.). Unit 1 is shown on the top line, while unit 2 is on the bottom. Unit 1 was exposed to its place field first (as indicated by $I$, written horizontally), while unit 2 was uncxposcd $(O)$. Following a number of sleeping and waking episodes, the order of exposure to place field was reversed. Each vertical column on the histogram represents one episode of a given behavior. Episodes are not necessarily of equal time length. The height of each column is proportional to the average firing rate during the given episode. For both unit 1 and unit 2 , the graph reveals increased firing rates during sleep following exposure to place field (Pexp) compared with rates in sleep following nonexposure (Pnexp) to place field. As shown in Figure 2, the effect was significant for the group of cells tested. 

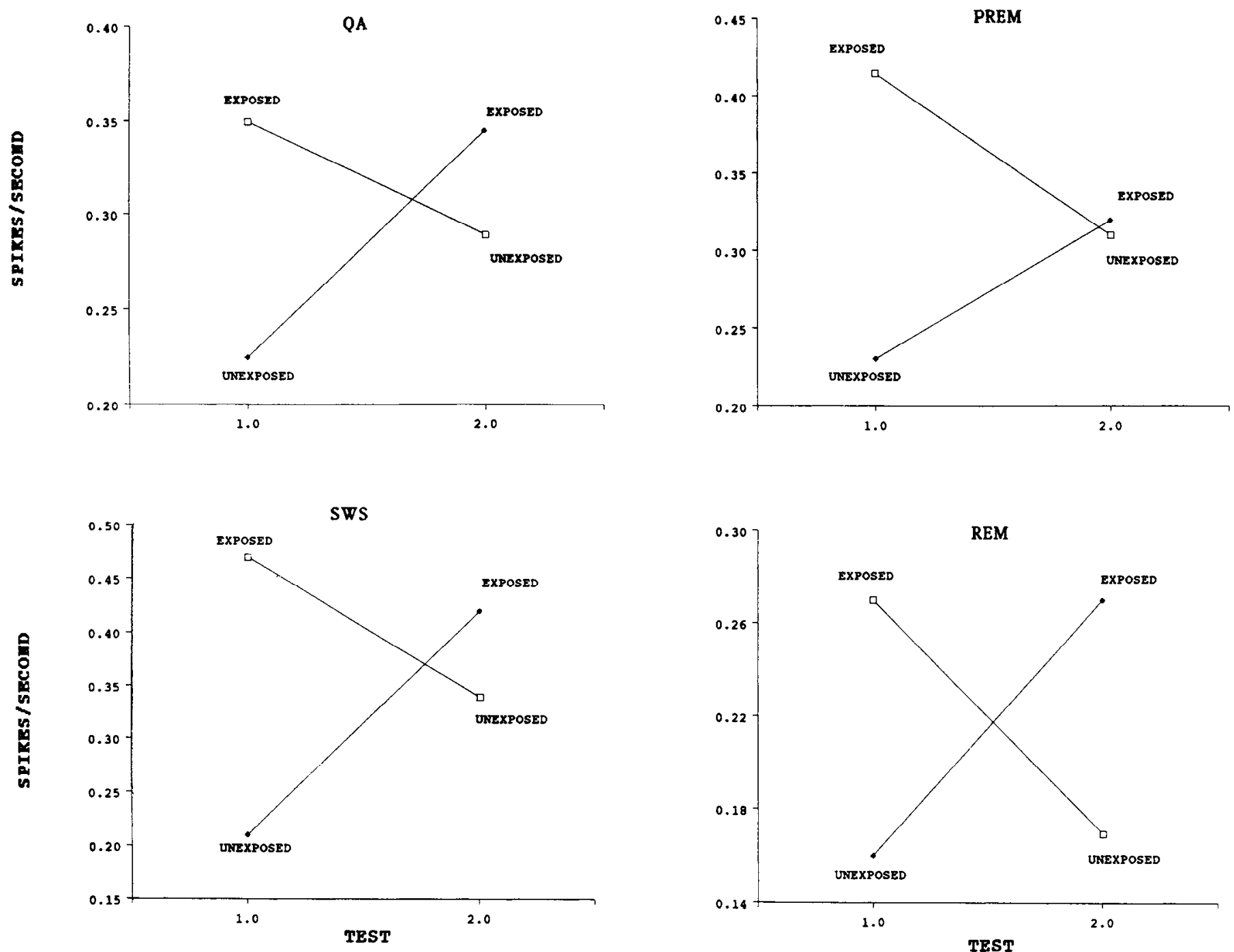

Figure 5. Line graph of unit firing for a representative pair of units recorded simultaneously and in a counterbalanced manner. The 4 graphs show each of the 4 sleeping states tested (SWS, PREM, and REM), as well as QA. Initially, one of the units (line of decreasing slope) was exposed to its place field (classified as an order 1 unit; see text), while the second was unexposed, followed by sleep at the center of the maze or a restricted part of the box (Test 1). Subsequently, the other unit (line of increasing amplitude) was exposed to its place field (classified as an order 2 unit), while the first was not, followed by sleep (Test 2). The figure shows that the counterbalancing procedure succeeded. The unit that was exposed first increased its firing in the subsequent sleep episodes, while the second unit's rate remained low. When the second unit was exposed, its rate increased in the sleep episodes that followed, while the first unit fired at a low rate.

parisons of the units' firing rate revealed that exposure to place field produced a significant increase in the firing rate of these cells in subsequent behaviors $[F(1,12)=6.57 ; p<0.02]$. A significant interaction between exposure and behavioral state was also found $[F(5,60)=2.40 ; p<0.05]$, indicating that, following exposure to place field, the cells did not increase their firing rates significantly for all behaviors tested but only for specific behaviors. Thus, simple effects analysis of behavior by stage using Tukey's method ( $a=0.05$ ) yielded significant postexposure effects for SWS, PREM, and REM. No postexposure changes were detected for the behavioral states of XPL, SAL, and QA. It should be noted, however, that the rate of firing in the QA state approached the level of significance $(p=0.05)$. [The simple effects analysis also revealed that, taking postexposure and post-nonexposure behavior as a whole, there were signfiicantly higher firing rates in SWS than in REM sleep (Schaffer-Welsch test; $p<0.05)$.] Thus, exposure of the cell to its place field, in the waking state, significantly increased its firing rate only in the sleep states but not the awake states that followed (see Fig. 2).

Figure 3 presents the average rate of firing of each of the individual cells post-nonexposure and postexposure to place field in the sleep states and QA. An increase in the firing rate, following exposure to place field, occurred in a large majority of place cells tested, leading to the overall significant increase in the firing rate noted above. In general, the increased firing during sleep appeared not to extend beyond an approximately $3 \mathrm{hr}$ period, during which time a number of SWS-REM episodes occurred (see Fig. 4; to be discussed below). A search (in a few units) for a systematic time course of the increased firing rate failed to reveal any such trend; i.c., for somc of the cclls the increased firing occurred within the first few sleep episodes following exposure, while other cells increased their firing rates during later episodes. Regardless, for most units there appeared to be a gradual decrease in firing during the last few intervals of the $2-3 \mathrm{hr}$ recording session. (It should be noted that the unit 
Figure 6. A. Average bursts per sccond, post-nonexposure and postexposure to place field. A significant main effect of exposure to place field was observed; however, the interaction of exposure and behavior failed to reach significance. Nonetheless, close inspection of the graph reveals that postexposure increases in the bursting rates took place only in SWS, PREM, and REM sleep. The failure to obtain a significant interaction is most likely due to the very large scatter seen for this variable (see Discussion). $B$, Average percent burst versus total events (bursts plus single spikes) post-nonexposure and postexposure to place field. No significant change was observed following cxposure to the place field. However, the percentage of bursts occurring in REM sleep more than doubled following exposure of the cells to their place fields. C, Average spikes per burst per second, post-nonexposure and postexposure to place ficld. A significantly higher number of spikes per burst occurred following exposure to place field in the SWS and REM states. $D$, Average number of single spikes, post-nonexposure and postexposure to place field. Although the interaction of exposure and behavioral state was not significant, the greatest increases in the number of single spikes were observed in the sleep states and QA. E, Average number of bursts containing 2 spikes, post-nonexposure and postexposure to place field. The number of bursts with 2 spikes did not change following exposure to place field for any of the behavioral states tested. $F$, Average number of bursts containing 3 spikes, post-nonexposure and postexposure to place field. A significant increase in the number of bursts with 3 spikes occurred following exposure to place ficld during the sleep states (SWS, PREM, and REM) but not for the other behavioral states tested.
A

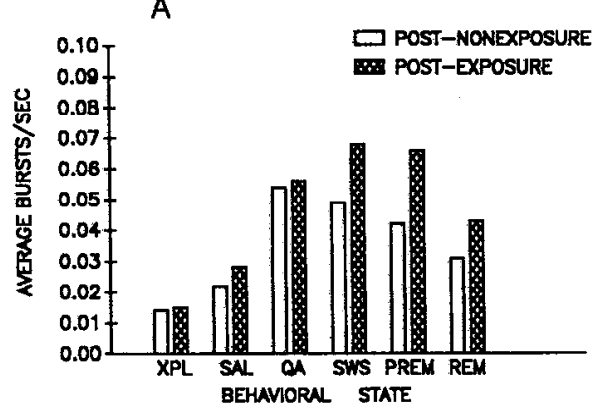

C

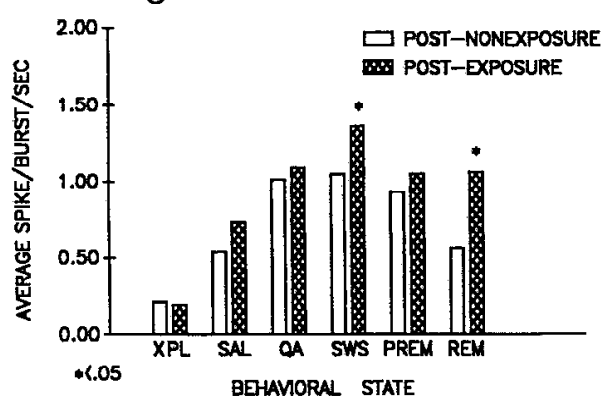

E

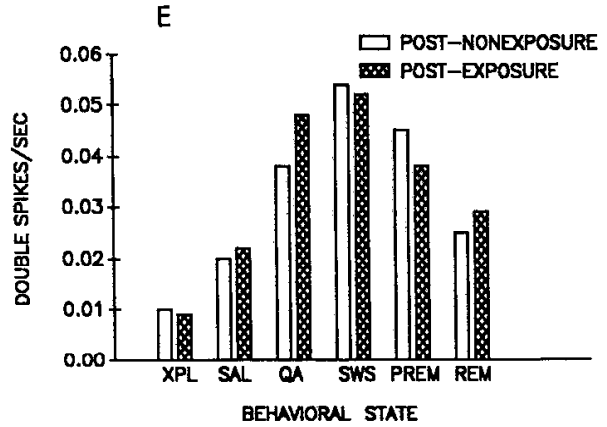

B

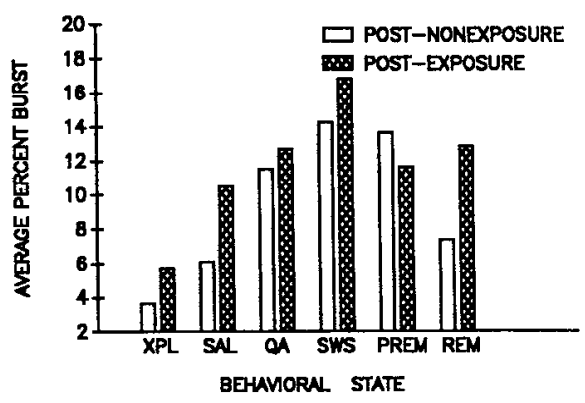

D

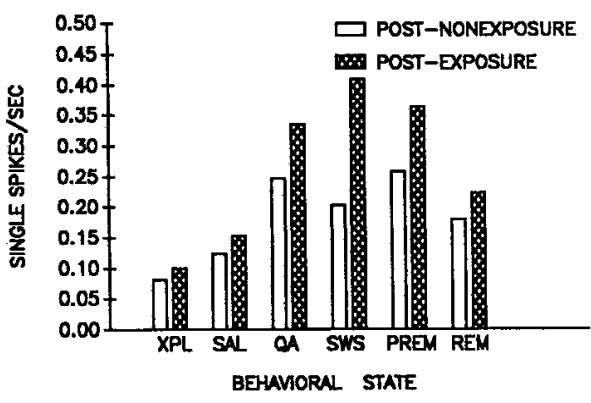

F

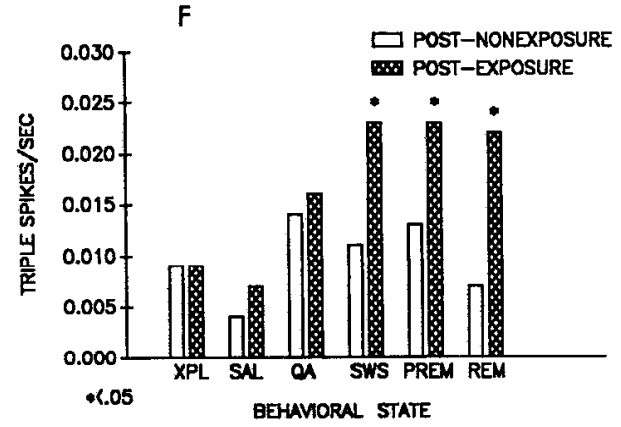

analysis was done off-line, and the decision for the length of recording was not influenced by the unit firing.)

Figure 4 illustrates a representative example of a pair of units (units 1 and 2) recorded simultaneously in a counterbalanced design. At first, unit 1 was exposed to its place field, as can be evidenced by the increased firing at the upper-leftmost corner (indicated by I, written horizontally). Following exposure of unit 1 , the animal engaged in a number of SWS-REM episodes, as well as a number of waking behaviors (on the center of the maze or box). The second unit was being recorded simultaneously, and the firing rates for this unit are shown on the bottom of the graph. Subsequently, the second unit was exposed to its place field (while the first unit was not), followed by sleep. The counterbalanced procedure used in this experiment was tested utilizing a 3-way analysis of variance, with the dependent variable being the rate of cell firing (spikes/sec) and the 3 factors being exposure to place field or not, behavioral state, and order of exposure to place field; i.e., for some of the cells the order of testing was exposed to place field followed by unexposed to place field, while for other cells, the order was unexposed to place field followed by exposed to place field. A significant interaction was achieved between exposure and order of testing $[F(1,11)=$ $6.43 ; p<0.05$ ]. [All units were classified as order 1 , exposed first in a pair or order 2 , exposed second in a pair. The interaction occurs because, considering the first test of the day, order 1 units fired at a high rate, while order 2 fired at a low rate. Considering the second test of the day the opposite was true (see Fig. 5).] The counterbalancing procedure succeeded. Taking all animals together, the units that were exposed first increased their firing in the subsequent behaviors, while the units that were not remained relatively inactive. When the second of a pair of units was later exposed to their place ficld, they then increased their firing rate in the slcep episodes that followed, while the first unit subsided to a baseline rate. Thus, for all animals, increased firing was determined by exposure and not by whether units were exposed first or second.

In addition to the effects observed on the rate of firing, detailed analysis of bursting and the number of spikes within a burst were performed. All bursts of a given behavior were included and divided by the total time the animal was engaged in that 
behavior, yielding average characteristics for a $1 \mathrm{sec}$ interval. The rates given for bursting, therefore, are similar to the rate of firing measurement and represent a density of bursting measure. An ANOVA performed on the bursts per second revealed results similar to those for the rate of firing. As shown in Figure $6 \mathrm{~A}$, increased bursting was observed following exposure of the cell to its place field $[F(1,12)=5.07 ; p<0.04]$. The interaction of exposure to place field by behavior, however, failed to achieve significance. Nonetheless, as seen in Figure $6 A$, the only bursting rates that increased notably were those of the SWS, PREM, and REM states. As with unit firing rate, a significant main effect of behavioral state was also observed $[F(5,55)=21.6 ; p<0.001]$. Taking postexposurc and post-noncxposurc bchavior as a wholc, significantly higher bursting rates were seen in SWS than in REM, SAL, or XPL.

The percentage of bursts versus total events (bursts + single spikes) was also analyzed. An analysis of variance performed on the postexposure percentage of bursts versus total events failed to detect significant main effects of exposure to place field $[F(1,11)=1.8 ; p>0.05]$. Thus, the percentage of bursts apparently did not differ following exposure to place field. Although the interaction of exposure and behavioral state was not significant $(p=0.08)$, and therefore, there was no significant increase in the postexposure sleep states in general, the postexposure percentage of bursts more than doubled during REM sleep. A significant main effect for behavioral state was obtained $[F(5,55)=9.05 ; p<0.001]$. A Schaffer-Welsch post hoc comparison $(a=0.05)$ revealed that, for behavior as a whole, significantly higher bursting occurred during SWS, PREM, and QA than in SAL and XPL (see Fig. 6B).

An increase was also observed in the rate of occurrence of bursts with multiple spikes following exposure of the units to their place field $[F(1,12)=4.61 ; p<0.05]$. A simple effects analysis (Tukey test; $a=0.05$ ) of exposure and behavioral state interaction revealed significant increases in the number of spikes per burst following exposure in the SWS and REM states but not in other behaviors. A significant main effect of behavioral state was also obtained $[F(5,60)=16.00 ; p<0.001]$. A SchafferWelsch post hoc analysis revealed that, for behavior as a whole, there were a higher number of spikes per burst during SWS than in SAL and XPL (see Fig. 6C).

Finer analysis of the number of spikes within a burst was also performed [i.e., single spike (no burst), double spikes, triple spikes, etc.]. ANOVA for each of the different number of spikes showed significant postexposure increases for the rate of single spikes $[F(1,12)=4.44 ; p<0.05]$. A significant interaction between exposure and behavior was not observed. However, the greatest increases occurred during the sleep states and QA. Significant main effects were seen for behavioral state $[F(5,60)=$ $15.83 ; p<0.001$ ]. Post hoc comparisons (Schaffer-Welsch test; $p<0.05$ ) showed that, considering both postexposure and postnonexposure behaviors, there were significantly higher rates in the occurrence of single spikes in SWS, PREM, and QA compared with XPL and SAL (see Fig. 6D). An ANOVA performed on the double-spike bursts failed to reach significance for exposure, indicating that the number of bursts with 2 spikes did not change following exposure to place field. Significant differences, however, were seen for behavioral state $[F(5,60)=13.68$; $p<0.001]$. For behavior as a whole, double spike bursts occurred significantly more often in SWS, PREM, and QA than in XPL and SAL (see Fig. $6 E$ ). The number of bursts with 3 spikes increased following exposure $[F(1,12)=6.00 ; p<0.03]$.
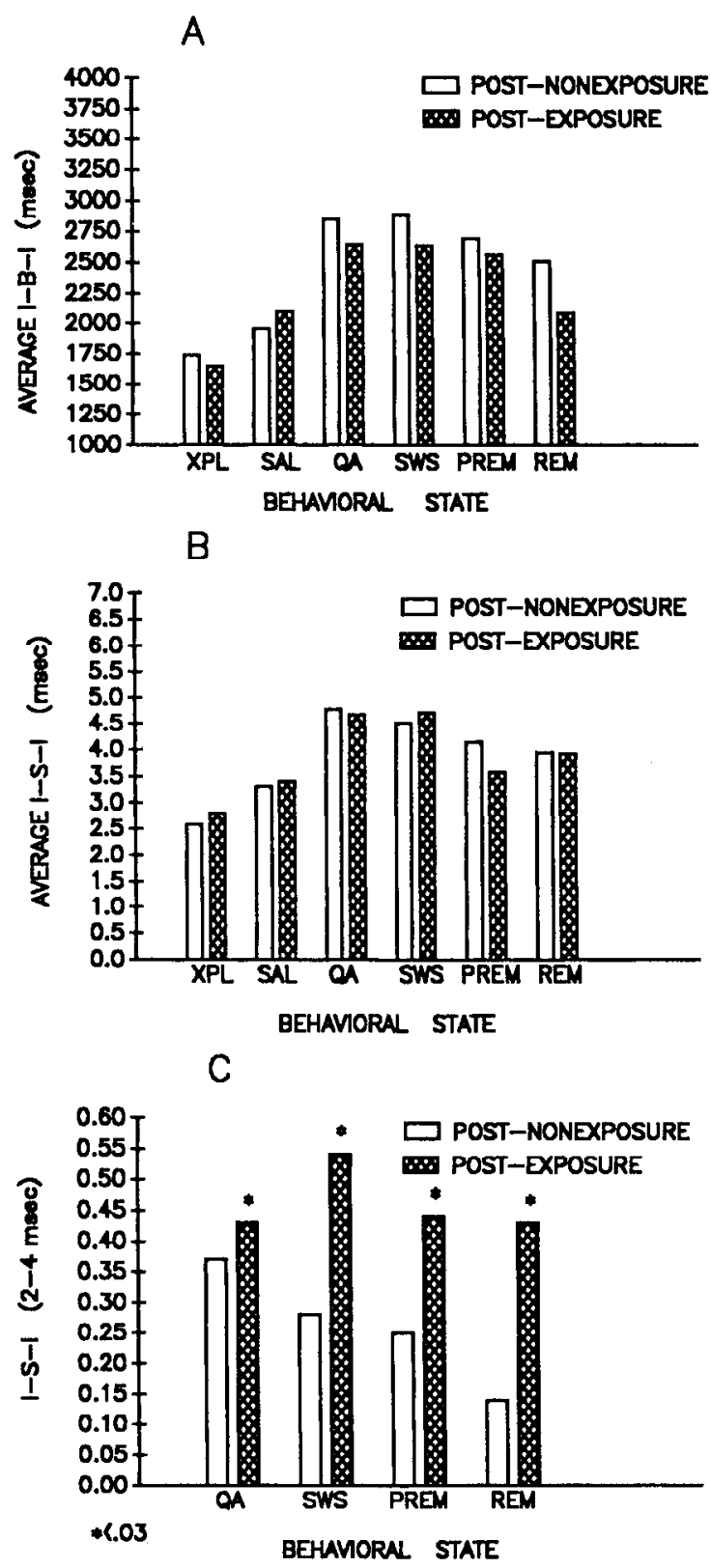

Figure 7. A, Average interburst interval, post-nonexposure and postexposure to place field. There were no significant changes in the interburst interval following exposure to place field. $B$, Average interspike interval post-nonexposure and postexposure to place field. No significant changes were observed following exposure. $C$, Closer analysis of the interspike intervals revealed significant increases falling in the 2-4 msec range postexposure to place field. These increases occurred for all of the sleep states and QA but not in SAL and XPL (not shown in the graph).

A significant interaction between stage of exposure and behavioral state was also achieved $[F(5,60)=2.79 ; p<0.02]$. A simple effects analysis using Tukey's method $(a=0.05)$ revealed a significant increase in the number of bursts composed of 3 spikes, following exposure, in the SWS, PREM, and REM states in comparison to the other states (see Fig. $6 F$ ).

Measurements were also made of the average IBI. An ANOVA performed on the average IBI post-nonexposure versus postexposure failed to achieve significance $[F(1,12)=2.17 ; p=$ 0.16] (see Fig. 7A). 
Another measure taken was the average ISI which represents the time interval between spikes, within a burst. An ANOVA performed on the postexposure average ISIs revealed no significant changes due to exposure of the unit to its place field (see Fig. $7 B$ ). The ISIs were also subdivided and analyzed in finer gradations $(0-2,2-4,4-6,6-8,8-10$, and 10-12 msec). Although no significant increases were observed in the average ISI, significant increases in the $2-4 \mathrm{msec}(250-500 \mathrm{~Hz})$ range were detected in the sleep states and QA following exposure of the cell to its place field $[F(1,12)=8.22 ; p<0.03]$. No other interval reached significance (see Fig. $7 \mathrm{C}$ ).

For a number of cells ( 5 out of 13), the animal was rewarded with a chocolate chip cookie when it occupied the place field of a particular place cell (i.e., while the cell was being exposed to its placc ficld). In almost all cascs, the animal, which had bcen given this kind of reward on previous days, consumed a large portion of the cookie during the course of the unit's exposure. The reward was introduced to see whether it would influence the unit's firing characteristics. Close observation of the inplace-field firing rates, of a number of cells, failed to show pronounced changes in the firing patterns due to the animal's consummatory behavior in the place field (i.e., it remained rather high as long as the animal occupied the cell's place field, regardless of his behavior or the reward). Similarly, significant effects were not detected in the firing rates of the "rewarded cells" in the subsequent sleep episodes $[F(1,9)=1.28 ; p>0.05]$. It should be noted, however, that the animal was rewarded with Noyes food pellets throughout the 8-arm maze over the extent of the experimental session and the chocolate chip cookies represented only a qualitatively different reward.

In summary, the main findings of this study were as follows. (1) There was a significant increase in the rate of firing of hippocampal complex spike (place) cells during the sleep states (SWS, PREM, and REM) following exposure of these cells to their place field. (2) There was a significant increase in the average number of spikes within a burst following exposure. This increase was evident only during the SWS and REM states. (3) There was a significant increase in the number of bursts with 3 spikes following exposure during the behavioral states of SWS, PREM, and REM. Finally, there was an increase in the number of bursts with the spikes falling in the $2-4 \mathrm{msec}$ ISI interval in all the sleeping states as well as QA.

\section{Discussion}

The results of the present experiment confirm our hypothesis that the awake unit activity of hippocampal place cells may influence the firing activity of these units in subsequent sleep states. Thus, the increased activity of these units in their place fields during the waking state enhanced their activity when the animal was engaged in sleep but not during the awake states that followed.

In detail, a significant increase in the firing rate was present during the sleeping but not the waking states following exposure. There was also a marked increase in the rate of bursting mainly during the SWS, PREM, and REM states (see Fig. 6A). However, on the basis of the absence of an interaction between exposure and behavioral state, it could not be determined whether the increased bursting occurred only in the sleeping behaviors. (A possible reason for the lack of a significant interaction was due to the high variability among the units.) Nonetheless, it is evident from Figure $6 A$ that the only behaviors that show an increase are those of SWS, PREM, and REM.
The average rate of occurrence of multiple spikes per burst also increased following exposure of the cell to its place field. These increases were evident only during the SWS and REM states. Closer analysis of the number of spikes within a burst revealed that the density of bursts containing 3 spikes increased significantly in the SWS, PREM, and REM states that followed exposure. Complex spike cells have been shown to fire in bursts containing as many as 7 or 8 spikes of decreasing amplitude (Ranck, 1973). Besides the single, double, and triple spikes reported in the results, measurements were also taken of the number of bursts containing 4,5 , and $6+$ spikes. These last 3 categories were excluded from the final analysis, however, due to the low frequency of their occurrence. Although long bursts occurred too infrequently to include in the present analysis, bursts with many spikes (4-10 l) wcre obscrved; in a small number of cells, bursts with as many as 15 spikes were also recorded.

Finally, there was a significant increase in the number of bursts with ISIs in the $2-4 \mathrm{msec}$ range. This increase was evident in all of the sleep states, as well as in QA but was especially noticeable during the SWS, PREM, and REM states. This interval corresponds to approximately $400 \mathrm{H} z$, which has been shown to be a rather sensitive frequency for inducing long-term potentiation (Winson and Dahl, 1986). Long-term potentiation has been hypothesized to be a mechanism underlying learning and memory and is thought to be a naturally occurring neuronal phenomenon (see discussion below).

In addition to the findings just cited, our recordings revealed that during tonic waking and sleeping behaviors, CA1 cells fire at their highest rates during SWS. They fire at considerably lower rates during REM. Such differential rates during sleep have been reported previously (Ranck, 1973; Olmstead et al., 1973; Suzuki and Smith, 1985a). We also observed, as did Ranck (1973), that during REM CA1 cells are silent for prolonged periods of time interspersed with short, intense bursts of firing. The present results also indicate that rewarding an animal while exposing a cell to its place field did not appear to have a pronounced effect either on the in-place-field firing or the firing rates in the sleeping states that followed. The insensitivity of these units to reward has been alluded to previously (O'Keefe, 1979).

As described in the introductory remarks, neuronal transmission through the hippocampal formation is dependent on the behavioral state of the animal, i.e., neuronal gating (Winson and Abzug, 1978). To recapitulate, through the use of field potential analysis, it was demonstrated that transmission of a stimulus from the perforant path through the CAl field of the hippocampal trisynaptic chain was restricted during waking states and REM (gate closed). Conversely, such transmission was totally unrestricted during the SWS state (gate open). Variable gating was seen in the 2 behavioral states accompanied by theta rhythm (in the rat) XPL and REM sleep.

The results of the present study largely confirm the findings reported using field potential analysis. In the tonic behavioral states, complex spike cells fire at a slow rate during the stillalert state and also during random exploration. (Complex spike cells, however, also fire in a phasic mode, namely, in place fields, which could not be detected using field potential analysis.) Unit firing is significantly higher during SWS and also during QA. [As noted, QA represents a drowsy state preceding SWS in which the EEG increases in amplitude, compared with the SAL state, and slow-wave spikes appear. As in SWS, neuronal transmission through the CAl field is relatively unrestricted during QA (Buz- 
saki, 1986).] In contrast, the firing rates during the REM state are significantly lower. This is comparable to some extent with the field potential studies showing that the CA1 field is open to transmission during SWS and closed during the waking states and REM. The present findings further extend the results of field potential analysis in that they suggest that the unrestricted neuronal transmission through the CA1 field during SWS may represent processing of information acquired during prior awake behavior. Thus, as reported above, when a rat was placed in a unit's place field and the unit increased its firing, there was also enhanced firing in the sleep states that followed. The enhanced unit activity was observed in all of the sleep states; the highest increases, however, occurred in SWS.

The role of sleep, and more specifically REM sleep, in memory consolidation has also been supported by REM-deprivation experiments in rats (Fishbein et al., 1971; Fishbein and Gutwein, 1977; Horne and McGrath, 1984). What came to be known as the REM memory-retention hypothesis suggests that memory remains labile until the occurrence of REM sleep. Keeping in mind that there are a number of methodological problems in the REM sleep deprivation experiments (see Ellman et al., 1978, for review), the majority of these studies suggest that REM sleep is a necessary prerequisite for memory consolidation to occur. The results obtained in the present study to some extent complement and add another dimension to the findings made in the REM sleep deprivation experiments. Our results also suggest that sleep (both SWS and REM) may play a role in the memoryconsolidation process.

A most important question concerning memory relates to its underlying cellular mechanisms. Long-term potentiation (LTP), the enhancement of synaptic facilitation by application of brief electrical stimulation to the perforant and intrahippocampal pathways has been proposed as a mechanism for mnemonic processes (Bliss and Lømo, 1973). If indeed hippocampal LTP is a naturally occurring phenomenon, it must be induced by entorhinal cortex and hippocampal cell firing. In light of this, the findings of the present studies are directly relevant. We have presented a complete descriptive analysis of hippocampal complex spike cell firing during the various waking and sleeping behavioral states, including the firing rate, the number of bursts, the IBIS, the number of spikes within a burst as well as the ISIs. Thus, our findings, for the first time, allow utilization of normally occurring patterns of $C A 1$ cell firing in the investigation of LTP (or other neural phenomena). With regard to LTP, the naturally occurring changes in firing pattern that occur in sleep following exposure to the place field appear to favor its induction. Longterm potentiation research has revealed 3 sensitive parameters for its induction. One way of effectively inducing LTP is by increasing the number of stimuli within the stimulus bursts that constitute the LTP stimulus train. The findings of the present study suggest that such a process may be happening physiologically in that there is an increase in the rate of the occurrence of multiple spike bursts in the sleeping behaviors following place field exposure. Second, LTP is induced more effectively by increasing the number of bursts that constitute the LTP stimulus train. An increased number of bursts were also seen in the present study after exposure of the cells to their place fields. Finally, there appears to be a frequency-sensitive effect in that a particularly cffective frequency for inducing LTP is $400 \mathrm{~Hz}-2.5 \mathrm{msec}$ ISI (Winson and Dahl, 1986). Following exposure of the place cells to their place fields, there was an increase in the number of bursts with ISIs in the $2-4 \mathrm{msec}$ range-approximately 400
$\mathrm{Hz}$. Thus, our present experiments reveal changes in cell firing characteristics which may be more likely to produce LTP in target areas of CA1 neurons during sleep, following exposure to a place field, and suggests that LTP may occur in a behaviorally dependent manner.

In summary, the experiments were undertaken in an attempt to further understand mnemonic processes at the neuronal level. Previous research dealing with memory suggests that its necessary prerequisite is the processing of information through the hippocampal trisynaptic chain, the last stage of which is the CA1 neuronal field. One possible interpretation of our results is that memory processing is evidenced, at least for the hippocampal place cells, by the enhancement of the firing characteristics that have been noted here during sleep, following active firing in the waking state.

\section{References}

Berger, T. W., P. C. Rinaldi, D. J. Weisz, and R. F. Thompson (1983) Single-unit analysis of differential hippocampal cell types during classical conditioning of the nictitating membrane response. J. Neurophysiol. 50: 1197-1219.

Best, P. J., and J. B. Ranck, Jr. (1982) The reliability of the relationship between hippocampal unit activity and sensory-behavioral events in the rat. Exp. Neurol. 75: 652-664.

Best, P. J., and L. T. Thompson (1984) Hippocampal cells which have place field activity also show changes in the activity during classical conditioning. Soc. Neurosci. Abstr. 10: 125.

Bliss, T. V. P., and T. Lømo (1973) Long-lasting potentiation of synaptic transmission in the dentate area of the anaesthetized rabbit following stimulation of the perforant path. J. Physiol. (Lond.) 232: 331-356.

Buzsaki, G. (1986) Hippocampal sharp waves: Their origin and significance. Brain Res. 398: 242-252.

Davis, H. P., J. Tribuna, W. T. Pulsinelli, and B. T. Volpe (1986) Reference and working memory of rats following hippocampal damage induced by transient forebrain ischemia. Physiol. Behav. 37: 387392.

Deadwyler, S. A., M. West, and G. Lynch (1979) Activity of dentate granule cells during learning: Differentiation of perforant path input. Brain Res. 169: 29-43.

DeJong, M. L. (1982) Apple II Assembly Language, H. W. Sams and Co., Indianapolis, IN.

Eichenbaum, H., M. Kuperstein, A. Fagan, and J. Nagode (1987) Cuesampling and goal-approach correlates of hippocampal unit activity in rats performing an odor-discrimination task. J. Neurosci. 7: 716732 .

Ellman, S. J., A. J. Spielman, D. Luck, S. S. Steiner, and R. Halperin (1978) REM deprivation: A review. In The Mind in Sleep: Psychology and Psychophysiology, A. M. Arkin, J. S. Antrobus, and S. J. Ellman, eds., pp. 419-458, Erlbaum, New York.

Fishbein, W., and B. M. Gutwein (1977) Paradoxical sleep and memory storage processes. Behav. Biol. 19: 425-464.

Fishbein, W., B. M. Gutwein, and J. R. Schwartz (1971) Retrograde amnesia: Electroconvulsive shock effects after termination of rapid eye movement sleep deprivation. Science 172: 80-82.

Hill, A. J. (1978) First occurrence of spatial firing in a new environment. Exp. Neurol. 62: 282-297.

Horne, J. A., and M. J. McGrath (1984) The consolidation hypothesis for REM sleep function: Stress and other confounding factors-a review. Biol. Psychol. 18: 165-184.

Kesner, R. P., K. Crutcher, and D. R. Beers (1988) Serial position curves for item (spatial location) information: Role of the dorsal hippocampal formation and medial septum. Brain Res. 454: 219226.

Kubie, J. L. (1984) A driveable bundle of microwires for collecting single-unit data from freely moving rats. Physiol. Behav. 32: 115118.

Kubie, J. L., and J. B. Ranck, Jr. (1983) Sensory-behavioral correlates of individual hippocampal neurons in three situations: Space and context. In Neurobiology of Hippocampus, W. Seifert, ed., pp. 433447, Academic, New York.

Micco, D. J., Jr. (1977) Lightweight, multi-contact, slip-ring com- 
mutator for recording and stimulating with small animals. Brain Res. Bull. 2: 499-502.

Mishkin, M., B. Malahut, and J. Bachevalier (1984) Memories and habits: Two neural systems. In Neurobiology of Learning and Memory, G. Lynch, J. L. McGaugh, and N. M. Weinberger, eds., pp. 6577, Guilford, New York.

Morris, R. G. M., P. Garrud, J. N. P. Rawlins, and J. O'Keefe (1982) Place navigation impaired in rats with hippocampal lesions. Nature 297: 681-683.

Muller, R. U., and J. L. Kubie (1987) The effects of changes in the environment on the spatial firing of hippocampal complex-spike cells. J. Neurosci. 7: 1951-1968.

Muller, R. U., J. L. Kubie, and I. B. Ranck, Ir. (1987) Spatial firing patterns of hippocampal complex-spike cells in a fixed environment. J. Neurosci. 7: 1935-1950.

O'Keefe, J. (1976) Place units in the hippocampus of the freely moving rat. Exp. Neurol. 51: 78-109.

O'Keefe, J. (1979) A review of the hippocampal place cells. Prog. Neurobiol. 13: 419-439.

O'Keefe, J. (1983) Spatial memory within and without the hippocampal system. In Neurobiology of the Hippocampus, W. Seifert, ed., pp. 193-403, Academic, New York.

O'Keefe, J., and D. H. Conway (1978) Hippocampal place units in the freely moving rat: Why they fire, where they fire. Exp. Brain Res. 31: 573-590.

O'Keefe, J., and J. Dostrovsky (1971) The hippocampus as a spatial map. Preliminary evidence from unit activity in the freely moving rat. Brain Res. 34: 171-175.

O'Keefe, J., and A. Speakman (1987) Single unit activity in the rat hippocampus during a spatial memory task. Exp. Brain Res. 68: 127.

Olmstead, C. E., P. J. Best, and L. E. Mays (1973) Neural activity in the dorsal hippocampus during paradoxical sleep, slow wave sleep and waking. Brain Res. 60: 381-391.

Olton, D. S. (1983) Memory functions and the hippocampus. In Neurobiology of the Hippocampus, W. Seifert, ed., pp. 335-373, Academic, New York.

Olton, D. S., and R. J. Samuelson (1976) Remembrance of places passed: Spatial memory in rats. J. Exp. Psychol. Anim. Behav. Proc. 2: 97-116.
Olton, D. S., M. Branch, and P. J. Best (1978) Spatial correlates of hippocampal unit activity. Exp. Neurol. 58: 387-409.

Pavlides, C., Y. J. Greenstein, M. Grudman, and J. Winson (1988) Long-term potentiation in the dentate gyrus is induced preferentially in the positive phase of theta rhythm. Brain Res. 439: 383-387.

Ranck, J. B., Jr. (1973) Studies on single neurons in dorsal hippocampal formation and septum in unrestrained rats. I. Behavioral correlates and firing repertoires. Exp. Neurol. 43: 461-531.

Segal, M., and J. Olds (1972) The behavior of units in the hippocampal circuit during learning. J. Neurophysiol. 35: 680-690.

Squire, L. R. (1986) Mechanisms of memory. Science 232: 1612-1619.

Squire, L. R., and S. Zola-Morgan (1983) The neurology of memory: The case for correspondence between the findings for human and nonhuman primate. In The Physiological Basis of Memory, J. A. Deutsch, ed., pp. 199-268, Academic, New York.

Suzuki, S. S., and G. K. Smith (1985a) Single-cell activity and synchronous bursting in the rat hippocampus during waking behaviors and sleep. Exp. Neurol. 89: 71-89.

Suzuki, S. S., and G. K. Smith (1985b) Burst characteristics of hippocampal complex spike cells in the awake rat. Exp. Neurol. 89: 9095.

Thompson, R. F., T. W. Berger, S. D. Berry, F. K. Hoeler, R. E. Kettnor, and D. J. Weisz (1980) Hippocampal substrate of classical conditioning. Physiol. Psychol. 8: 262-279.

Wible, C. G., R. L. Findling, M. Shapiro, E. J. Lang, S. Crane, and D. S. Olton (1986) Mnemonic correlates of unit activity in the hippocampus. Brain Res. 399: 97-110.

Winson, J., and C. Abzug (1978) Neuronal transmission through hippocampal pathways dependent on behavior. J. Neurophysiol. 41: 716732.

Winson, J., and D. Dahl (1986) Long-term potentiation in dentate gyrus: Induction by asynchronous volleys in separate afferents. Science $234: 985-988$.

Zola-Morgan, S., L. R. Squire, and D. G. Amaral (1986) Human amnesia and the medial temporal region: Enduring memory impairment following a bilateral lesion limited to the CAl field of the hippocampus. J. Neurosci. 6: 2950-2967. 